\title{
Role of Reactive Oxygen Intermediates in Cellular Responses to Dietary Cancer Chemopreventive Agents
}

Author

Affiliation
Jedrzej Antosiewicz' ${ }^{1}$, Wieslaw Ziolkowski ${ }^{1}$, Siddhartha Kar², Anna A. Powolny ${ }^{3}$, Shivendra V. Singh ${ }^{2,3}$

Department of Bioenergetics and Physiology of Exercise, Medical University of Gdansk, Gdansk, Poland

University of Pittsburgh Cancer Institute University of Pittsburgh School of Medicine, Pittsburgh, Pennsylvania, USA

Department of Pharmacology, University of Pittsburgh School of Medicine, Pittsburgh, Pennsylvania, USA

\author{
Key words \\ - organosulfur compounds \\ - isothiocyanates \\ isoflavones \\ - curcumin \\ - ROS \\ - apoptosis \\ - chemoprevention
}

received April 3, 2008

revised May 22, 2008

accepted June 2, 2008

\section{Bibliography}

Dol $10.1055 / \mathrm{s}-2008-1081307$ Planta Med 2008; 74: 15701579

(c) Georg Thieme Verlag KG Stuttgart · New York Published online July 31, 2008 ISSN 0032-0943

\section{Correspondence}

Prof. Dr. Shivendra V. Singh 2.32A Hillman Cancer Center Research Pavilion 5117 Centre Avenue Pittsburgh

Pennsylvania 15213 USA

Tel.: +1-412-623-3263

Fax: +1-412-623-7828

singhs@upmc.edu

\section{Abstract \\ $\nabla$}

Epidemiological studies continue to support the premise that diets rich in fruits and vegetables may offer protection against cancer of various anatomic sites. This correlation is quite persuasive for vegetables including Allium (e.g., garlic) and cruciferous (e.g., broccoli and watercress) vegetables. The bioactive food components responsible for the cancer chemopreventive effects of various edible plants have been identified. For instance, the anticancer effects of Allium and cruciferous vegetables are attributed to organosulfur compounds (e.g., diallyl trisulfide) and isothiocyanates (e.g., sulforaphane and phenethyl isothiocyanate), respectively. Bioactive food components with anticancer activity are generally considered to be antioxidants due to their ability to modulate expression/activity of antioxidative and phase 2 drug-metabolizing enzymes and scavenging free radicals. At the same time, more recent studies have provided convincing evidence to indicate that certain dietary cancer chemopreventive agents cause generation of reactive oxygen species (ROS) to trigger signal transduction culminating in cell cycle arrest and/or programmed cell death (apoptosis). Interestingly, the ROS generation by some dietary anticancer agents is tumor cell specific and does not occur in normal cells. This review summarizes experimental evidence supporting the involvement of ROS in cellular responses to cancer chemopreventive agents derived from common edible plants.

\section{Abbreviations \\ $\nabla$}

AITC: allyl isothiocyanate

ARE: antioxidant response element

BITC: benzyl isothiocyanate

DAS: diallyl sulfide

DADS: diallyl disulfide

DATS: diallyl trisulfide

DR5: death receptor 5

ERK: extracellular signal-regulated kinase

ITCs: isothiocyanates

JNK: c-Jun N-terminal kinase

MMP: mitochondrial membrane potential

NAC: $\quad N$-acetylcysteine

OSCs: organosulfur compounds

PEITC: phenethyl isothiocyanate

ROS: reactive oxygen species

SAC: $\quad S$-allylcysteine

SAMC: S-allylmercaptocysteine

\section{Introduction}

$\nabla$

Nutrition has long been suspected to play an important role in cancer etiology. Accumulating evidence suggests that diet, in addition to cancercausing substances, contains many cancer-preventive agents [1], [2], [3]. This implies that many cancers can be prevented by changes in dietary habits. It is becoming increasingly clear that many dietary agents can retard or prevent the process of carcinogenesis with reduced cancer outcomes by multiple mechanisms, including (i) enhanced detoxification of the carcinogenic intermediates through induction of phase 2 enzymes, (ii) reduced carcinogen activation due to suppression of cytochrome P450-dependent monooxygenases, (iii) selective promotion of apoptosis (cell death) in cancer cells but not in normal epithelial cells, and (iv) perturbations in cell cycle progression in cancer cells [3], [4], [5], [6]. The cancer-protective effect of food constituents is also supported by epidemiological data. For example, the epidemiological evidence for the cancer-protective effect of cruciferous vege- 
tables (e.g., broccoli) and Allium vegetables (e.g., garlic) is quite strong [7], [8]. In recent years, many studies have demonstrated strong chemopreventive and possibly cancer-chemotherapeutic effects of whole food and bioactive food components against cancers of the skin, lung, breast, colon, liver, stomach, prostate, and other sites [3], [9]. The promising dietary chemopreventive compounds, which have demonstrated anticancer effects in more than one tumor model, include (-)-epigallocatechin gallate in green tea, resveratrol in grapes, lupeol in fruits such as mango, delphinidin in pigmented fruits, curcumin in turmeric, sulforaphane and other isothiocyanates (ITCs) in cruciferous vegetables, organosulfur compounds (OSCs) in Allium vegetables, lycopene in tomato, and genistein in soy, among many others [3], [5], [9].

The dietary cancer-chemopreventive agents are considered antioxidants due to their ability to modulate the level/activity of antioxidants and phase 2 drug-metabolizing enzymes [3], [7], [9], [10]. For example, cancer-chemopreventive OSCs derived from Allium vegetables not only cause induction of phase 2 drug-metabolizing enzymes including glutathione transferases and quinone reductase but also increase glutathione levels and glutathione peroxidase activity in the liver as well as extrahepatic tissues of mice [11], [12], [13]. More recent studies have indicated that many bioactive food components suppress growth of cancer cells in vitro as well as in vivo by causing cell cycle arrest and apoptosis induction [9], [10], [14], [15], [16]. Interestingly, cellular responses to some dietary cancer chemopreventive agents correlate with generation of reactive oxygen species (ROS). This review focuses on the role of ROS in signal transduction leading to cell cycle arrest and apoptosis induced by various dietary cancer chemopreventive agents.

\section{Allium-Derived Organosulfides}

\section{Occurrence}

The cancer-chemopreventive effect of Allium vegetables (e.g., garlic, onions, scallions, chives, leeks) is attributed to OSCs that are generated upon processing (cutting or chewing) of these vegetables [17]. The primary sulfur compound in intact garlic is $\gamma$ glutamyl-S-alk(en)yl-l-cysteine, which is hydrolyzed and oxidized to yield alliin [17], an odorless precursor of the OSCs. Processing of garlic bulb releases a vacuolar enzyme alliinase, which acts on alliin to give rise to extremely unstable and odoriferous compounds including allicin. Allicin and other thiosulfinates decompose to oil-soluble OSCs including diallyl sulfide (DAS), diallyl disulfide (DADS), diallyl trisulfide (DATS), dithiins, and ajoene [17]. Several water-soluble OSCs, including S-allyl cysteine (SAC) and $S$-allylmercaptocysteine (SAMC), are also derived from Allium vegetables.

\section{Evidence for cancer chemoprevention}

Initial evidence for an anticancer effect of Allium vegetables came from population-based epidemiological studies [18], [19], [20]. For example, You et al. [18] reported a significant reduction in gastric cancer risk with increasing intake of Allium vegetables in a population-based, case-control study. Similarly, Steinmetz et al. [19] observed an inverse correlation between intake of fruits and vegetables and colon cancer risk in the Iowa Women's Health Study. Preclinical animal studies have indicated that OSCs can offer protection against chemically induced cancers [21], [22], [23], [24], [25]. For example, Belman [21] was the first to show that topical application of the essential oil of garlic inhibited the incidence of tumor promoted by phorbol myristate acetate. Cancer chemoprevention by OSCs has been observed against benzo[ $a]$ pyrene-induced forestomach and pulmonary cancer in mice, dimethylhydrazine-induced colon cancer and $\mathrm{N}$ nitrosomethylbenzylamine-induced esophageal cancer in rats, and azoxymethane-induced colon carcinogenesis in rats [22], [23], [24]. Elucidation of the mechanisms by which OSCs may prevent carcinogenesis has been a favorite subject of research for the past 20 years. On one hand, cancer chemoprevention by OSCs is, at least in part, believed to be due to their ability to modulate levels of antioxidants and phase 2 drug-metabolizing enzymes. In HepG2 cells, OSC-mediated induction of NQO1 and heme oxygenase 1 was mediated by Nrf2 [25]. The antioxidant response element (ARE) activation and Nrf2 protein accumulation by OSCs correlated with phase 2 gene expression induction [25]. The structure-activity analysis indicated a critical role for the third sulfur in the OSC for its bioactivity [25]. In experiments involving transient transfection of HepG2 cells with mutant Nrf2, the DATS-induced ARE activity was inhibited by dominant-negative Nrf2 Kelch-like ECH-associating protein 1 and constructs [25]. At the same time, several OSCs have been shown to suppress cancer cell growth in vitro and in vivo in association with ROS generation leading to cell cycle arrest and apoptosis induction [14], [26]. The anti- and pro-oxidant effects of OSCs are summarized below.

\section{Antioxidative effects}

The Allium vegetable-derived OSCs exhibit antioxidant activity [11], [12], [13], [27], [28], [29], [30], [31]. Some of them are simply free radical scavengers, while others increase cellular antioxidant potential by inducing antioxidant enzymes. For example, treatment of mice with DAS, DADS, and DATS resulted in elevation of glutathione levels and induction of glutathione transferase and quinone reductase expression in the liver, lung, and/or forestomach [11], [12], [13]. The DADS administration ameliorated gentamicin-induced oxidative stress and nephropathy in rats in vivo [27]. The hydrogen peroxide-mediated injury in neuronally differentiated PC12 cells was significantly attenuated by pretreatment with $20 \mu \mathrm{M}$ DADS, which correlated with increased cell survival, activation of Akt, inactivation of GSK-3, and inhibition of cytochrome $c$ release and caspase-3 activation [28]. Attenuation of carbon tetrachloride-induced oxidative stress and pulmonary fibrosis in rats by oral administration of SAC has also been reported [29]. SAC administration prevented the carbon tetrachloride-induced depletion of glutathione levels, the increase in inducible nitric oxide synthase expression, the infiltration of leukocytes, and ROS generation [29]. SACmediated protection against cerebral ischemic injury due to scavenging of endogenously and exogenously generated peroxynitrite and inhibition of extracellular signal-regulated kinase (ERK) has also been reported [30]. Kim et al. [31] showed that SAC, but not DAS, DADS, or DATS, offered neuroprotection in an in vitro ischemia model. DATS and DADS, but not DAS, were shown to reduce lipopolysaccharide-induced expression of inducible nitric oxide synthase, nitric oxide production, oxidative stress, and nuclear factor-kappaB (NF-kappaB) activation in RAW 264.7 macrophages [32]. NF-kappaB is a transcription factor that not only regulates gene expression of a number of prosurvival (antiapoptotic) proteins but also is constitutively activated in a variety of hematological and solid tumor cells [33]. However, studies are needed to determine whether the anticarcino- 
genic effects of OSCs are, at least in part, mediated by suppression of NF-kappaB activation. Some of the antioxidative effects of OSCs are summarized in $\bullet$ Table 1.

\section{Role of ROS in signal transduction}

More recent studies have suggested a critical role for ROS in cellular responses to OSCs. For instance, Filomeni et al. [34] showed that DADS-induced apoptosis in SH-SY5Y neuroblastoma cell lines correlated with ROS generation. The oxidative insult resulted in protein and lipid damage and activation of redox-sensitive c-Jun N-terminal kinase (JNK) [34]. DADS-mediated activation of JNK in SH-SY5Y cells was linked to ROS-dependent dissociation of glutathione transferase from JNK, as activation of JNK and apoptosis were attenuated by a spin trap and overexpression of copper/zinc-superoxide dismutase [34]. These results suggested a critical role for ROS in JNK activation and apoptosis by DADS [34]. Studies from our own laboratory have shown that apoptosis induction by DATS in human prostate cancer cells is associated with ROS-dependent activation of JNK [35]. DATS-mediated ROS production, JNK activation, and/or apoptosis in human prostate cancer cells were significantly attenuated by overexpression of catalase or pretreatment with N-acetyl-cysteine (NAC) [35], [36]. It is interesting to note that a normal prostate epithelial cell line (PrEC) is significantly more resistant to growth inhibition and apoptosis induction by DATS compared with prostate cancer cells [35], [36]. The precise mechanism for selective killing of prostate cancer cells by DATS is not clear, but the possibility that resistance of normal prostate epithelial cells to apoptosis by DATS is due to the lack of ROS generated cannot be ignored. ROS-mediated activation of stress kinases, including JNK, in apoptotic response to DADS has also been observed in human glioblastoma T98G and U87MG cells [37]. Even though several studies suggest a tight link between ROS generation, JNK activation, and apoptosis by OSCs [34], [35], [36], [37], the precise mechanism by which OSCs cause JNK activation is not fully understood. Similarly, the signaling events downstream of ROS generation and JNK activation in OSC-mediated apoptosis remain elusive.

Structure-activity studies from our laboratory have revealed important roles for allyl groups as well as the oligosulfide chain length in cellular responses to OSCs [35], [38]. We found that the growth inhibition by OSCs against prostate cancer cells increases with an increase in the number of sulfur atoms [35]. For example, DATS is a significantly more potent suppressor of prostate cancer cell proliferation compared with DADS, whereas DAS, dipropyl sulfide, and dipropyl disulfide are practically inactive [35]. Studies have indicated that exposure of cancer cells to OSCs results in $\mathrm{G}_{2} / \mathrm{M}$ phase cell cycle arrest. The above structureactivity relationship is also observed for OSC-mediated $\mathrm{G}_{2} / \mathrm{M}$ phase cell cycle arrest [38]. The $\mathrm{G}_{2} / \mathrm{M}$ phase cell cycle arrest has been observed for DADS and DATS in human colon, prostate, and lung cancer cells [34], [38], [39], [40], [41]. DADS- and DATS-induced $\mathrm{G}_{2} / \mathrm{M}$ phase cell cycle arrest was markedly suppressed in the presence of NAC, suggesting that cell cycle arrest by garlic compounds is also dependent on ROS production [38], [41]. However, it is unclear whether the protection offered by NAC is due to suppression of ROS generation or because of chemical reactivity between NAC and DATS. Even though the precise mechanism by which ROS contribute to DADS-mediated cell cycle arrest is not clear, we have shown previously that DATS-mediated cell cycle arrest and downregulation and Ser-216 phosphorylation of the cell cycle regulatory phosphatase Cdc25C were significantly attenuated by pretreatment with NAC [38]. These results suggest that ROS generation may cause oxidative modification of Cdc25C to regulate its degradation. However, further studies are needed to substantiate this possibility. Hosono et al. [40] have documented that DATS can cause specific oxidative modification of cysteine residues Cys-12 and Cys-354 of beta-tubulin in a cellfree system. DATS treatment has been shown to disrupt the microtubule network in human colon cancer cells [40]. However, it remains to be seen whether DATS causes oxidative modification of beta-tubulin cysteine in vivo. More recent studies from our laboratory have revealed that DATS treatment disrupts the microtubule network in human prostate cancer cells [42]. Moreover, DATS-treated human prostate cancer cells were arrested in prometaphase in a checkpoint kinase 1-dependent manner [42], [43]. Because checkpoint kinase 1 is an intermediary of DNA damage checkpoints [44], it is possible that DATS-mediated activation of checkpoint kinase 1 is caused by ROS-dependent DNA damage. Additional work is needed to experimentally verify this speculation. Pinto and co-workers have also suggested that beta-elimination reactions with cysteine $S$-conjugates in garlic may modify cancer cell growth by targeting redox-sensitive signal proteins and thereby regulating cellular responses [45]. Examples of ROS-linked cellular responses to selected OSCs are summarized in $\bullet$ Table 2.

The mechanism of ROS generation by DADS is not clear, but we have shown recently that DATS-mediated ROS production, at least in human prostate cancer cells, is linked to an increase in the labile iron pool [46]. DATS-induced ROS generation, $\mathrm{G}_{2} / \mathrm{M}$ phase cell cycle arrest and degradation, and hyperphosphorylation of Cdc25C were significantly attenuated in the presence of EUK134, a combined mimetic of superoxide dismutase and catalase [46]. Interestingly, DATS-induced ROS generation and $\mathrm{G}_{2} / \mathrm{M}$ phase cell cycle arrest were also inhibited significantly in the presence of desferrioxamine (DFO), an iron chelator, but this protection was not observed with iron-saturated DFO. DATS

Table 1 Antioxidative effects of Allium vegetable-derived organosulfur compounds

$\begin{array}{lll}\text { Compound } & \text { Antioxidative effect } & \text { Reference } \\ \text { DAS, DADS, DATS } & \begin{array}{l}\text { Increase in glutathione level and glutathione redox-cycle } \\ \text { enzymes, induction of phase } 2 \text { enzymes (glutathione transferases and quinone reductase) in liver, } \\ \text { lung, and/or forestomach of mice }\end{array} & \text { [11], [12], [13] } \\ \text { DADS } & \text { Protection against gentamicin-induced oxidative stress and neuropathy in rats } & \text { [27] } \\ \text { DADS } & \begin{array}{l}\text { Protection against hydrogen peroxide-mediated cytotoxicity in PC12 cells neuronally differentiated } \\ \text { by nerve growth factor }\end{array} & {[28]} \\ \text { DATS } & \begin{array}{l}\text { Reduction of lipopolysaccharide-induced expression of iNOS, nitric oxide production, oxidative } \\ \text { stress, and activation of NF-kappa-B in RAW 264.7 macrophages }\end{array} & {[32]} \\ \text { SAC } & \text { Protection of cerebral ischemia in vitro and neuroprotection in vivo } & \text { [30], [31] } \\ \text { SAC } & \text { Protection against carbon tetrachloride-induced oxidative stress and pulmonary fibrosis in rats } & {[29]}\end{array}$


Table 2 Examples of ROS-linked cellular responses to organosulfides

\begin{tabular}{|c|c|c|c|}
\hline Agent & Cell line & ROS-linked cellular responses & Reference \\
\hline DADS & SH-SY5Y neuroblastoma & $\begin{array}{l}\text { - ROS generation } \\
\text { - JNK activation, apoptosis } \\
\text { - Protein and lipid damage }\end{array}$ & [34] \\
\hline DATS & $\begin{array}{l}\text { PC- } 3 \text { and DU145 human } \\
\text { prostate cancer }\end{array}$ & $\begin{array}{l}\text { - ROS generation } \\
\text { - JNK activation, apoptosis } \\
\text { - Protection against JNK activation and apoptosis by overexpression of } \\
\text { catalase and in the presence of NAC }\end{array}$ & [35] \\
\hline DATS & $\begin{array}{l}\text { LNCaP human prostate } \\
\text { cancer }\end{array}$ & $\begin{array}{l}\text { - ROS generation } \\
\text { - Apoptosis induction } \\
\text { - Protection against ROS generation and apoptosis in the presence of a } \\
\text { combined mimetic of catalase and SOD }\end{array}$ & [36] \\
\hline DADS/DATS & $\begin{array}{l}\text { T98G and U87MG human } \\
\text { glioblastoma }\end{array}$ & $\begin{array}{l}\text { - ROS generation } \\
\text { - Activation of JNK and p38 MAPK } \\
\text { - Apoptosis } \\
\text { - Increase in ER stress }\end{array}$ & [37] \\
\hline DATS & $\begin{array}{l}\text { HCT-15 and DLD-1 human } \\
\text { colon cancer }\end{array}$ & $\begin{array}{l}\text { - } \mathrm{G}_{2} / \mathrm{M} \text { phase cell cycle arrest followed by apoptosis } \\
\text { - Activation of caspase-3 } \\
\text { - Disruption of microtubule network }\end{array}$ & {$[40]$} \\
\hline DATS & $\begin{array}{l}\text { PC-3 and DU145 human } \\
\text { prostate cancer }\end{array}$ & $\begin{array}{l}\text { - ROS generation } \\
\text { - } \mathrm{G}_{2} / \mathrm{M} \text { phase and mitotic arrest } \\
\text { - Degradation and increased } \mathrm{S} 216 \text { phosphorylation of } \mathrm{Cdc} 25 \mathrm{C} \\
\text { - Protection of } \mathrm{G}_{2} / \mathrm{M} \text { arrest, and degradation and } \mathrm{S} 216 \text { phosphorylation } \\
\text { of } \mathrm{Cdc} 25 \mathrm{C} \text { in the presence of NAC } \\
\text { - Activation of checkpoint kinase } 1 \text { (Chk } 1 \text { ) } \\
\text { - Attenuation of mitotic arrest by knockdown of Chk } 1 \\
\text { - ROS generation linked to increased labile iron pool due to degradation } \\
\text { of ferritin }\end{array}$ & [38], [42], [46] \\
\hline
\end{tabular}

treatment caused a marked increase in the level of labile iron that was accompanied by degradation of the light chain of the iron-storage protein ferritin [46]. To our surprise, DATS-mediated degradation of ferritin, the increase in the labile iron pool, ROS generation, and/or cell cycle arrest were significantly attenuated by ectopic expression of a catalytically inactive mutant of JNK kinase 2 as well as RNA interference of stress-activated protein kinase/extracellular signal-regulated kinase 1 [46]. These results provided convincing evidence to suggest the existence of a novel pathway involving the JNK signaling axis in the regulation of DATS-induced ROS generation. However, further studies are needed to determine whether this pathway is specific for prostate cancer cells and unique to DATS. In an in vitro study, di-, tri-, and tetrasulfides generated hydrogen peroxide in the presence of GSH and hemoglobin and caused oxidative damage to erythrocytes [47]. The activity decreased in the order of tetra- $>$ tri- > disulfide [47]. It remains to be seen whether a similar mechanism is operative in cancer cells.

\section{Cruciferous Vegetable-Derived Isothiocyanates \\ $\nabla$}

\section{Occurrence}

Like Allium vegetables, the evidence is quite strong for a cancerprotective effect of the vegetables of the family Cruciferae [7], [15], [47]. Commonly known edible cruciferous vegetables include broccoli, watercress, cabbage, kale, horseradish, radish, turnip, and garden cress. The cancer-chemopreventive effect of cruciferous vegetables is attributed to ITCs, which occur naturally as thioglucoside conjugates (glucosinolates) and distinguish them from other vegetables [48]. The ITCs are hydrolysis products of glucosinolates and are generated through catalytic mediation of myrosinase, which is released upon processing (cutting or chewing) of cruciferous vegetables from a compartment separated from glucosinolates [48]. Evidence exists for conversion of glucosinolates to ITCs in the gut [48]. ITCs have a common basic skeleton but differ in their terminal R group, which can be an alkyl, an alkenyl, an alkylthioalkyl, an aryl, a $\beta$-hydroxyalkyl, or an indolylmethyl group [48]. At least 120 different glucosinolates have been identified. The widely studied ITCs include sulforaphane, phenethyl isothiocyanate (PEITC), benzyl isothiocyanate (BITC), and allyl isothiocyanate (AITC).

\section{Evidence for cancer chemoprevention}

In addition to epidemiological evidence [7], [49], [50], laboratory studies have indicated that ITCs provide highly effective protection against cancer in animal models, induced by a variety of chemical carcinogens, including tobacco smoke-derived chemicals [15], [47]. For example, the anticancer effects of sulforaphane [(-)-1-isothiocyanato-(4R)-(methylsulfinyl)-butane, a naturally occurring s-isomer], which is present in rather high concentrations in broccoli, are well documented [51], [52], [53], [55], [56]. Cancer chemoprevention by s-sulforaphane or its synthetic analogue (racemic D,L-isomer) has been observed against 9,10-dimethyl-1,2-benzanthracene-induced mammary cancer in rats, azoxymethane-induced colonic aberrant crypt foci in rats, benzo[a]pyrene-induced forestomach cancer in mice, and 7,12-dimethylbenz[a]anthracene/12-O-tetradecanoylphorbol 13-acetate-induced skin tumorigenesis in mice [51], [52], [53], [55]. More recently, sulforaphane administration was shown to significantly inhibit lung metastasis induced by B16F-10 melanoma cells in C57BL/6 mice [56]. The mechanism by which sulforaphane inhibits chemically induced cancers may involve impairment of carcinogen activation through inhibition of cytochrome P450 and/or acceleration of inactivation of carcinogenic intermediates through induction of phase 2 enzymes [57], [58]. 
Similarly, BITC and PEITC have been shown to inhibit chemically induced cancers in animal models. For example, BITC is a potent inhibitor of rat mammary and mouse lung carcinogenesis induced by the polycyclic hydrocarbons 7,12-dimethylbenz $[a]$ anthracene and benzo[a]pyrene, respectively [59], [60]. Studies have indicated that even a subtle change in ITC structure could have a significant impact on its anticancer activity. For instance, pulmonary tumor induction by benzo[a]pyrene in A/J mice is inhibited significantly by BITC but not by PEITC, which is a close structural analogue of BITC [15], [47]. Thus, caution must be exercised in extrapolation of results from one ITC compound to the others. Although certain ITC compounds have also been shown to promote bladder tumorigenesis in rats [61], available epidemiological and preclinical data are mostly in favor of a cancer-protective effect of dietary ITCs [7], [15], [47], [50]. In addition to preventing chemically induced cancers, several ITC compounds have also been shown to inhibit growth of cancer cells in vivo. In vivo anticancer effects have been reported for sulforaphane [62], [63], PEITC [64], [65] and AITC [66]. The in vivo growth inhibitory effects of sulforaphane, PEITC, and AITC correlate with apoptosis induction [62], [64], [65], [66]. As discussed below, recent studies have indicated that ROS act as key signaling intermediates in apoptosis induction by ITCs.

\section{Role of ROS in signal transduction}

Similar to Allium vegetable-derived organosulfides, the ITCs (e.g., sulforaphane) act indirectly to boost the antioxidant capacity of the cells by increasing expression of phase 2 enzymes [67], [68]. The enzymes upregulated by sulforaphane include Nrf2-regulated genes, including glutathione transferase, quinone reductase, and heme oxygenase- 1 , which can function as protectors of oxidative stress [67], [68]. In addition, sulforaphane was shown to offer powerful and prolonged protection of human retinal pigment epithelial cells, keratinocytes, and mouse leukemia cells against the cytotoxic effects of several oxidants including menadione, tert-butyl hydroperoxide, 4-hydroxynonenal, and peroxynitrite [69]. Sulforaphane and its close structural analogues erucin and iberin have been shown to upregulate thioredoxin reductase 1 , which has broad substrate specificity and can reduce many low-molecular-weight compounds, including hydrogen peroxide and lipid hydroperoxides, in MCF-7 human breast cancer cells [70]. The same group of investigators showed subsequently that sulforaphane not only is a potent inducer of thioredoxin reductase 1 but also can upregulate its substrate thioredoxin [71]. BITC treatment inhibited excessive superoxide generation in inflammatory leukocytes [72]. Thus, it is reasonable to conclude that sulforaphane and possibly other ITCs may function as indirect antioxidants by modulating cellular redox status.

Evidence also exists to indicate that treatment of cells with ITCs results in a transient burst of ROS, which seem to signal cellular responses to this class of dietary phytochemicals. The ROS-dependent cellular responses to ITC exposure are summarized in - Table 3. The ROS generation in response to ITC treatment was first documented for BITC in rat liver epithelial RL34 cells [73]. Interestingly, these investigators also showed that BITC-mediated induction of glutathione transferase Pi was tightly linked to ROS generation [73], as ROS generation and induction of glutathione transferase Pi expression were found to be significantly inhibited by pretreatment of cells with glutathione [73]. These observations suggest that even the antioxidant effect of ITCs may be, at least in part, related to a cellular adaptive response to ITC-induced ROS generation. In a follow-up study, the same group of investigators reported a strong correlation between ROS generation and apoptosis induction by BITC in RL34 cells [74]. BITC-mediated ROS production in RL34 cells was associated with inhibition of mitochondrial respiration, mitochondrial swelling, and release of cytochrome $c$ [74]. This was the first published report to document a mitochondrial redox-sensitive mechanism in BITC-mediated apoptosis [74]. Sulforaphane was shown to increase the transcript and protein levels of multidrug resistance-associated protein 2 , an efflux pump contributing to biliary secretion of xenobiotics, in primary rat and human hepatocytes in an ROS-dependent manner [75]. Our studies have indicated that ROS generation is a critical event in apoptosis induction by sulforaphane in human prostate cancer cells [76]. Exposure of PC-3 cells to growth-suppressive concentrations of sulforaphane resulted in ROS generation that was accompanied by disruption of the mitochondrial membrane potential, cytosolic release of cytochrome $c$, and apoptosis. All these effects were significantly blocked by pretreatment with NAC as well as ectopic expression of catalase [76]. The sulforaphane-induced ROS generation was also significantly attenuated by pretreatment with mitochondrial respiratory chain complex I inhibitors, including diphenyleneiodonium chloride and rotenone [76]. These results suggested that mitochondria are involved in sulforaphane-induced ROS generation in human prostate cancer cells [76]. However, further studies are needed to systematically explore this possibility. Sulforaphane-mediated apoptosis in the human pancreatic cancer cell lines MIA PaCa- 2 and PANC- 1 also correlated with ROS generation, as NAC treatment conferred significant protection against cell death [77]. Likewise, sulforaphane-mediated DNA fragmentation in HepG2 cells was significantly attenuated by NAC and catalase [78]. Subtoxic doses of sulforaphane sensitized hepatoma cells to apoptosis induction by tumor necrosis factor-related apoptosis-inducing ligand (TRAIL), which correlated with ROS generation and induction of death receptor 5 mRNA and protein [79]. Pretreatment with NAC and catalase overexpression attenuated sulforaphane-induced upregulation of death receptor 5 and nearly completely blocked apoptosis by the sulforaphane and TRAIL combination [79]. These results indicated that sulforaphane-induced ROS production and subsequent upregulation of death receptor 5 were critical for triggering and amplifying TRAIL-induced apoptosis [79]. In DU145 human prostate cancer cells, sulforaphane treatment resulted in a rapid and transient burst of ROS followed by apoptotic cell death, both of which were blocked by pretreatment of cells with NAC [80]. The positive correlation between ROS generation and apoptosis induction has also been observed for PEITC in human prostate cancer cells [65] and for BITC in human breast cancer cells [81]. The ROS production as well as apoptosis by PEITC and BITC were significantly attenuated in the presence of the combined superoxide dismutase and catalase mimetic Euk134 [65], [81]. Trachootham et al. [82] have suggested that abnormal increases in ROS can be exploited by PEITC to selectively kill cancer cells. Oncogenic transformation of ovarian epithelial cells with $H-R s^{\mathrm{V} 12}$ or expression of Bcr-Abl in hematopoietic cells not only caused ROS generation but also rendered the malignant cells highly sensitive to PEITC [82]. Excessive ROS generation resulted in oxidative mitochondrial damage, inactivation of redox-sensitive molecules, and cell death [82]. Collectively, these studies provide convincing experimental evidence to implicate ROS in signal transduction leading to programmed cell death by several structurally different ITC compounds in different cell types [76], [77], [78], [79], [80], [81]. It is interesting to 
Table 3 ROS-linked cellular responses to cancer-chemopreventive isothiocyanates

\begin{tabular}{|c|c|c|c|}
\hline Agent & Cell line & ROS-linked cellular responses & Reference \\
\hline BITC & Rat liver RL34 cell line & $\begin{array}{l}\text { - Apoptosis induction } \\
\text { - Depletion of glutathione levels }\end{array}$ & [74] \\
\hline Sulforaphane & $\begin{array}{l}\text { Primary rat and human } \\
\text { hepatocytes }\end{array}$ & $\begin{array}{l}\text { - Increase in MRP2 mRNA and protein expression } \\
\text { - Attenuation of ROS production and MRP2 induction by dimethyl } \\
\text { sulfoxide }\end{array}$ & [75] \\
\hline Sulforaphane & $\begin{array}{l}\text { PC-3 and DU145 human } \\
\text { prostate cancer cells }\end{array}$ & $\begin{array}{l}\text { - Depletion of GSH levels } \\
\text { - Loss of mitochondrial membrane potential (MMP) } \\
\text { - Caspase-9/3 activation } \\
\text { - Apoptosis induction } \\
\text { - Attenuation of ROS generation, MMP collapse, caspase activation, } \\
\text { and apoptosis by pretreatment with NAC and/or overexpression of } \\
\text { catalase }\end{array}$ & [76] \\
\hline Sulforaphane & $\begin{array}{l}\text { MIA PaCa- } 2 \text { and PANC- } 1 \\
\text { human pancreatic cancer } \\
\text { cells }\end{array}$ & $\begin{array}{l}\text { - ROS production } \\
\text { - Loss of MMP } \\
\text { - Depletion of glutathione level } \\
\text { - Apoptosis induction } \\
\text { - Protection against loss of plasma membrane integrity and MMP in } \\
\text { the presence of NAC }\end{array}$ & [77] \\
\hline Sulforaphane & HepG2 hepatoma cell line & $\begin{array}{l}\text { - Apoptosis induction } \\
\text { - Abrogation of cell death by pretreatment with NAC and catalase }\end{array}$ & [78] \\
\hline Sulforaphane & $\begin{array}{l}\text { Hep3B, Huh-7, and HepG2 } \\
\text { human hepatoma cells }\end{array}$ & $\begin{array}{l}\text { - Sensitization of hepatoma cells to apoptosis induction by TRAIL } \\
\text { - Induction of death receptor } 5 \text { (DR5) } \\
\text { - ROS production } \\
\text { - Attenuation of ROS generation, DR5 induction, and cell death by } \\
\text { pretreatment with NAC and overexpression of catalase }\end{array}$ & [79] \\
\hline Sulforaphane & $\begin{array}{l}\text { DU145 human prostate } \\
\text { cancer cell line }\end{array}$ & $\begin{array}{l}\text { - ROS generation } \\
\text { - Apoptosis } \\
\text { - Attenuation of ROS generation and DNA fragmentation in the } \\
\text { presence of NAC }\end{array}$ & {$[80]$} \\
\hline BITC & $\begin{array}{l}\text { MDA-MB-231 and MCF-7 } \\
\text { human breast cancer cells }\end{array}$ & $\begin{array}{l}\text { - ROS generation } \\
\text { - Apoptosis induction } \\
\text { - Abrogation of ROS generation and apoptosis induction by } \\
\text { pretreatment with a combined superoxide dismutase and catalase } \\
\text { mimetic Euk134 }\end{array}$ & {$[81]$} \\
\hline PEITC & $\begin{array}{l}\text { Oncogenically transformed } \\
\text { hematopoietic cells }\end{array}$ & $\begin{array}{l}\text { - ROS production } \\
\text { - Cell death } \\
\text { - Oxidative damage to cardiolipin } \\
\text { - Glutathione depletion } \\
\text { - Attenuation of ROS production and cell death by pre-incubation } \\
\text { with exogenous catalase } \\
\text { - Abrogation of glutathione depletion by pre-incubation with NAC } \\
\text { and catalase }\end{array}$ & {$[82]$} \\
\hline PEITC & $\begin{array}{l}\text { PC-3 human prostate cancer } \\
\text { cell line }\end{array}$ & $\begin{array}{l}\text { - ROS generation } \\
\text { - MMP collapse } \\
\text { - Apoptotic DNA fragmentation } \\
\text { - Attenuation of ROS generation, MMP loss, and DNA fragmentation } \\
\text { by pre-incubation with Euk134 }\end{array}$ & {$[65]$} \\
\hline
\end{tabular}

note that the aromatic ITCs (PEITC and BITC) are relatively more potent inducers of ROS production and apoptosis than is sulforaphane, an alkylthioalkyl ITC [65], [76], [81]. It remains to be seen whether the differential potencies of aromatic ITCs and sulforaphane for apoptosis induction are related solely to differences in their abilities to cause ROS production. Further investigation is also desired to elucidate the signaling events downstream of ROS generation in the execution of apoptosis by ITCs as well as to gain insight into the mechanism of ITC-mediated ROS generation. For example, it remains to be determined whether alteration in iron homeostasis contributes to ITC-induced ROS generation. Nonetheless, it is reasonable to conclude that ROS serve as key signaling intermediates in apoptosis induction by the ITC family of cancer-chemopreventive agents.

\section{ROS-Dependent Signaling by Other Bioactive Food Components $\nabla$}

ROS-linked cellular responses in cancer cells are not unique to Allium vegetable-derived OSCs or cruciferous vegetable-derived ITCs. Experimental evidence that links ROS generation with signal transduction in cancer cells by three highly promising and widely studied bioactive food components (genistein, capsaicin, and curcumin) is described below, illustrating the importance of ROS in cancer chemoprevention by dietary agents.

Apoptosis and growth inhibition caused by a fermented soy product has been related to increased ROS generation, and both processes were inhibited by catalase and an iron chelator [83]. In the isolated rat liver mitochondria model, the soy constituent 
genistein caused swelling, loss of mitochondrial membrane potential, and release of accumulated calcium [84]. Moreover, mitochondrial permeability transition pore opening caused by this soy isoflavone was mediated by ROS due to their interaction with the respiratory chain at the level of complex III [84]. Likewise, apoptosis induction by capsaicin (8-methyl- $N$-vanillyl-6nonenamide), the major pungent component of red pepper, in Jurkat cells is linked to ROS generation and JNK activation [85]. The growth inhibitory effect of capsaicin on H-ras-transformed human breast epithelial cells was related to overexpression of Rac1, and NAC reversed capsaicin-induced growth inhibition [86]. Capsaicin treatment induced apoptosis in human cutaneous squamous cell carcinoma cell lines, and cell death and ROS generation caused by this agent were significantly decreased in respiration-deficient cells [87]. Curcumin [1,7 bis(4-hydroxy-3methoxyphenol)-1,6-heptadiene-3,5-dione] is another widely studied bioactive food component derived from the rhizome of the plant Curcuma longa. Curcumin exhibits both antioxidant and pro-oxidative properties [88], [89], [90], [91], [92]. For instance, curcumin at concentrations ranging between 3 and 30 $\mu \mathrm{M}$ was able to induce ROS production in cancerous human submandibular adenocarcinoma cells and, to a smaller extent, in normal human primary gingival fibroblasts [92]. Antioxidants including glutathione and NAC or the hydroxyl radical scavenger mannitol significantly reduced curcumin-induced ROS generation [90], [91], [92]. The pro-oxidative effect of curcumin was observed in another study where increased ROS formation was associated with a decrease in GSH concentration [93]. In contrast, curcumin at 12.5 - to $25-\mu \mathrm{M}$ concentrations reduced ROS formation in human myeloid leukemia cells but elevated ROS levels at higher concentrations [94].

\section{Concluding Remarks and Future Directions $\nabla$}

ROS are at the crossroads of cancer chemoprevention and carcinogenesis. On one hand, as discussed above, pro-apoptotic signal transduction by many dietary cancer-chemopreventive agents relies on ROS production. On the other hand, endogenous ROS production is relatively high in tumor cells compared with normal cells as a result of oncogenic signaling through the NADPH oxidase and by the mitochondria. Genetic knockdown of $\mathrm{Cu}, \mathrm{Zn}$ SOD, or decreased Mn-SOD activity in mice promotes cancer development [95], [96]. In addition, catalase knockout mice are more susceptible to cancer development [97]. Finally, embryonic fibroblasts lacking peroxiredoxin-1 express higher levels of cmyc oncogene and ROS generation [98]. The fact that tumor cells have higher ROS generation can be exploited for therapeutic purposes. One strategy is to increase ROS scavenging, thereby inhibiting ROS-mediated mitogenic signaling in cancer cells. The feasibility of this strategy has been confirmed by experiments where superoxide dismutase, glutathione peroxidase, or catalase overexpression was found to inhibit tumor growth [99], [100].

Because oxidative stress is implicated in the pathogenesis of many chronic diseases including cancer, the potential side effects of ROS production by bioactive food components cannot be ignored. For example, hydroxyl radicals can produce purine, pyrimidine, and deoxyribose oxidation products [101], [102], [103]. Oxidative DNA damage relevant to cancer development by other reactive oxygen intermediates (e.g., peroxynitrite) has also been suggested [53], [104], [105], [106]. ROS can also exert a wide range of cellular effects through modulation of signaling pathways that influence neoplastic transformation as well as cancer cell proliferation. The steady-state level of different ROS represents a plausible determinant for their cellular responses. Cancer chemoprevention by dietary agents including DATS and ITCs may involve both protection against oxidative DNA modification, due to their ability to boost antioxidant defense in normal cells/tissues [11], [12], [13], and signal transduction leading to growth arrest and apoptosis in cancer cells [34], [35], [36], [39]. Validation of this speculation awaits further investigation. It is also possible that normal epithelial cells are relatively more resistant to dietary cancer chemopreventive agent-induced ROS generation compared with malignant cells, which may explain the resistance of normal epithelial cells to cell death caused by these agents. Further studies are needed to systematically explore this possibility as well.

We are tempted to speculate that ROS generation by bioactive food components with proven cancer chemopreventive efficacy, at least in preclinical cellular and animal models, may not be deleterious because (i) these chemicals (e.g., OSCs and ITCs) are derived from vegetables consumed by humans on a daily basis, yet epidemiological studies continue to support the idea that dietary intake of these vegetables may reduce cancer risk [7], [8]; (ii) long-term administration of these phytochemicals to rodents does not cause weight loss or any other signs of toxicity [65], [107]; and (iii) normal epithelial cells appear resistant to ROS generation and/or apoptosis induction by some of these phytochemicals [35], [36], [82], [108]. It is possible that the ROS generation by these phytochemicals in cancer cells serves to trigger a signaling cascade that leads to growth arrest and cell death.

Even though it is clear that ROS serve as critical intermediates in signal transduction by several bioactive food components, the mechanism by which ROS production occurs is poorly understood for many of these phytochemicals. Also, the events downstream of ROS generation in cellular responses to bioactive food components remain elusive. Understanding the processes leading to ROS formation and their specific action on signaling pathways will likely help optimize the cancer chemopreventive regimens involving these agents.

\section{Acknowledgements}

$\nabla$

The work cited in this review from our laboratory was supported by National Cancer Institute grants CA129347, CA115498, CA113363, and CA101753.

\section{References}

1 Sporn MB. Chemoprevention of cancer. Lancet 1993; 342: 1211 - 3

2 Wattenberg $L W$. Inhibitors of chemical carcinogenesis. Adv Cancer Res 1978; 26: $197-226$

3 Kelloff GJ. Perspectives on cancer chemoprevention research and drug development. Adv Cancer Res 2000; 78: 199-334

4 World Cancer Research Fund. Food, nutrition and the prevention of cancer: a global perspective. Washington DC: American Institute for Cancer Research; 1997

5 Milner JA. Molecular targets for bioactive food components. J Nutr 2004; 134: 2492S-8S

6 Liu RH. Health benefits of fruit and vegetables and from additive and synergistic combinations of phytochemicals. Am J Clin Nutr 2003; 78: $517 s-20 s$

7 Verhoeven DTH, Goldbohm RA, van Poppel G, Verhagen $H$, van den Brandt PA. Epidemiological studies on Brassica vegetables and cancer risk. Cancer Epidemiol Biomarkers Prev 1996; 5: 733-48 
8 Challier B, Perarnau JM, Viel JF. Garlic, onion and cereal fiber as protective factors for breast cancer: a French case-control study. Eur J Epidemiol 1998; 14 : 737 - 47

9 Davis CD, Milner JA. Diet and cancer prevention. In: Temple NJ, Wilson T, Jacobs DV, editors. Nutritional health: strategies for disease prevention Totowa: Humana Press; 2006: 151 - 71

10 Surh YJ. Cancer chemoprevention with dietary phytochemicals. Nat Rev Cancer 2003; 3: 768-80

$11 \mathrm{Hu}$ X, Benson PJ, Srivastava SK, Mack LM, Xia H, Gupta V et al. Glutathione S-transferases of female $\mathrm{A} / \mathrm{J}$ mouse liver and forestomach and their differential induction by anti-carcinogenic organosulfides from garlic. Arch Biochem Biophys 1996; 336: 199-214

12 Singh SV, Pan SS, Srivastava SK, Xia H, Hu X, Zaren HA et al. Differential induction of $\mathrm{NAD}(\mathrm{P}) \mathrm{H}$ :quinone oxidoreductase by anti-carcinogenic organosulfides from garlic. Biochem Biophys Res Commun 1998; 244: $917-20$

13 Singh SV, Mack LM, Xia H, Srivastava SK, Hu X, Benson PJ et al. Differential induction of glutathione redox-cycle enzymes by anti-carcinogenic organosulfides from garlic. Clin Chem Enzymol Commun 1997; 7: $287-97$

14 Herman-Antosiewicz A, Singh SV. Signal transduction pathways leading to cell cycle arrest and apoptosis induction in cancer cells by Allium vegetable-derived organosulfur compounds: a review. Mutat Res 2004; 555: 121 - 31

15 Hecht SS. Chemoprevention of cancer by isothiocyanates, modifiers of carcinogen metabolism. J Nutr 1999; 129: 768 - 74

16 Shishodia S, Chaturvedi MM, Aggarwal BB. Role of curcumin in cancer therapy. Curr Probl Cancer 2007; 31: 243 - 305

17 Amagase H, Petesch BL, Matsuura H, Kasuga S, Itakura Y. Intake of garlic and its bioactive components. J Nutr 2001; 131: 955S-62S

18 You WC, Blot WJ, Chang YS, Ershow A, Yang ZT, An Q et al. Allium vegetables and reduced risk of stomach cancer. J Natl Cancer Inst 1989; 81: $162-4$

19 Steinmetz KA, Kushi LH, Bostick RM, Folsom AR, Potter JD. Vegetables, fruit, and colon cancer in the Iowa Women's Health Study. Am J Epidemiol 1994; 139: 1 - 15

20 Hsing AW, Chokkalingam AP, Gao YT, Madigan MP, Deng J, Gridley G et al. Allium vegetables and risk of prostate cancer: a population-based study. J Natl Cancer Inst 2002; 94: 1648-51

21 Belman $S$. Onion and garlic oils inhibit tumor promotion. Carcinogenesis 1983; 4: $1063-5$

22 Wargovich MJ. Diallyl sulfide, a flavor component of garlic (Allium sativum) inhibits dimethylhydrazine-induced colon cancer. Carcinogenesis 1987; 8: $487-9$

23 Sparnins VL, Barany G, Wattenberg LW. Effects of organosulfur compounds from garlic and onions on benzo[a]pyrene-induced neoplasia and glutathione S-transferase activity in the mouse. Carcinogenesis 1989; 9: $131-4$

24 Wargovich MJ, Woods C, Eng VWS, Stephens LC, Gray K. Chemoprevention of $\mathrm{N}$-nitrosomethylbenzylamine-induced esophageal cancer in rats by the naturally occurring thioether, diallyl sulfide. Cancer Res 1988: $48: 6872-5$

25 Chen C, Pung D, Leong V, Hebbar V, Shen G, Nair S et al. Induction of detoxifying enzymes by garlic organosulfur compounds through transcription factor Nrf2: effect of chemical structure and stress signals. Free Radic Biol Med 2004; 37: 1578 - 90

26 Herman-Antosiewicz A, Powolny AA, Singh SV. Molecular targets of cancer chemoprevention by garlic-derived organosulfides. Acta Pharmacol Sin 2007; 28: 1355 - 64

27 Pedraza-Chaverrí J, González-Orozco AE, Maldonado PD, Barrera D, Medina-Campos ON, Hernández-Pando R. Diallyl disulfide ameliorates gentamicin-induced oxidative stress and nephropathy in rats. Eur J Pharmacol 2003; 18: $71-8$

28 Koh SH, Kwon H, Park KH, Ko JK, Kim JH, Hwang MS et al. Protective effect of diallyl disulfide on oxidative stress-injured neuronally differentiated PC12 cells. Brain Res Mol Brain Res 2005; 133: 176- 86

29 Mizuguchi S, Takemura S, Minamiyama Y, Kodai S, Tsukioka T, Inoue K et al. S-allyl cysteine attenuated $\mathrm{CCl} 4$-induced oxidative stress and pulmonary fibrosis in rats. Biofactors 2006; 26: 81 -92

30 Kim JM, Lee JC, Chang N, Chun HS, Kim WK. S-Allyl-L-cysteine attenuates cerebral ischemic injury by scavenging peroxynitrite and inhibiting the activity of extracellular signal-regulated kinase. Free Radic Res 2006; 40: 827 - 35

31 Kim JM, Chang HJ, Kim WK, Chang N, Chun HS. Structure-activity relationship of neuroprotective and reactive oxygen species scavenging activities for allium organosulfur compounds. J Agric Food Chem 2006; 54: $6547-53$

32 Liu KL, Chen HW, Wang RY, Lei YP, Sheen LY, Lii CK. DATS reduces LPSinduced iNOS expression, NO production, oxidative stress, and NF- $\kappa \mathrm{B}$ activation in RAW 264.7 macrophages. J Agric Food Chem 2006; 54: $3472-8$

33 Ravi R, Bedi A. NF- $\mathrm{B}$ in cancer - a friend turned foe. Drug Resist Updat 2004; 7: $53-67$

34 Filomeni G, Aquilano K, Rotilio G, Ciriolo MR. Reactive oxygen speciesdependent c-Jun NH2-terminal kinase/c-Jun signaling cascade mediates neuroblastoma cell death induced by diallyl disulfide. Cancer Res 2003; 63: 5940-9

35 Xiao D, Choi D, Johnson DE, Vogel VG, Johnson CS, Trump DL et al. Diallyl trisulfide-induced apoptosis in human prostate cancer cells involves c-Jun N-terminal kinase and extracellular-signal regulated kinasemediated phosphorylation of Bcl-2. Oncogene 2004; 23: 5594-606

36 Kim YA, Xiao D, Xiao H, Powolny AA, Lew KL, Reilly ML et al. Mitochondria-mediated apoptosis by diallyl trisulfide in human prostate cancer cells is associated with generation of reactive oxygen species and regulated by Bax/Bak. Mol Cancer Ther 2007; 6: 1599-609

37 Das A, Banik NL, Ray SK. Garlic compounds generate reactive oxygen species leading to activation of stress kinases and cysteine proteases for apoptosis in human glioblastoma T98G and U87MG cells. Cancer 2007; 110: 1083 - 94

38 Xiao D, Herman-Antosiewicz A, Antosiewicz J, Xiao H, Brisson M, Lazo JS et al. Diallyl trisulfide-induced $\mathrm{G}_{2}-\mathrm{M}$ phase cell cycle arrest in human prostate cancer cells is caused by reactive oxygen species-dependent destruction and hyperphosphorylation of Cdc25C. Oncogene 2005; 24: $6256-68$

39 Knowles LM, Milner JA. Diallyl disulfide inhibits p34(cdc2) kinase activity through changes in complex formation and phosphorylation. Carcinogenesis 2000; 21: 1129-34

40 Hosono T, Fukao T, Ogihara J, Ito Y, Shiba H, Seki T et al. Diallyl trisulfide suppresses the proliferation and induces apoptosis of human colon cancer cells through oxidative modification of beta-tubulin. J Biol Chem 2005; 280: 41487-93

$41 \mathrm{Wu}$ XJ, Kassie F, Mersch-Sundermann $\mathrm{V}$. The role of reactive oxygen species (ROS) production on diallyl disulfide (DADS) induced apoptosis and cell cycle arrest in human A549 lung carcinoma cells. Mutat Res 2005; 579: $115-24$

42 Herman-Antosiewicz A, Singh SV. Checkpoint kinase 1 regulates diallyl trisulfide-induced mitotic arrest in human prostate cancer cells. J Biol Chem 2005; 280: 28519-28

43 Herman-Antosiewicz A, Stan SD, Hahm ER, Xiao D, Singh SV. Activation of a novel ataxia-telangiectasia mutated and Rad3 related/checkpoint kinase 1-dependent prometaphase checkpoint in cancer cell by diallyl trisulfide, a promising cancer chemopreventive constituent of processed garlic. Mol Cancer Ther 2007; 6: 1249-61

44 Liu Q, Guntuku S, Cui XS, Matsuoka S, Cortez D, Tamai Ket al. Chk1 is an essential kinase that is regulated by Atr and required for the $\mathrm{G}(2) / \mathrm{M}$ DNA damage checkpoint. Genes Dev 2000; 14: 1448 - 59

45 Pinto JT, Krasnikov BF, Cooper AJL. Redox-sensitive proteins are potential targets of garlic-derived mercaptocysteine derivatives. J Nutr 2006; 136: 835S-41S

46 Antosiewicz J, Herman-Antosiewicz A, Marynowski SW, Singh SV. c-Jun $\mathrm{NH} 2$-terminal kinase signaling axis regulates diallyl trisulfide-induced generation of reactive oxygen species and cell cycle arrest in human prostate cancer cells. Cancer Res 2006; 66: 5379- 86

47 Munday R, Munday JS, Munday CM. Comparative effects of mono-, ditri-, and tetrasulfides derived from plants of the Allium family: redox cycling in vitro and hemolytic activity and Phase 2 enzyme induction in vivo. Free Radic Biol Med 2003; 34: 1200-11

48 Fahey JW, Zalcmann AT, Talalay P. The chemical diversity and distribution of glucosinolates and isothiocyanates among plants. Phytochemistry $2001 ; 56: 5-51$

49 Cohen JH, Kristal AR, Stanford JL. Fruit and vegetable intakes and prostate cancer risk. J Natl Cancer Inst 2001; 92: 61 -8

50 Ambrosone $C B$, McCann SE, Freudenheim JL, Marshall JR, Zhang $Y$, Shields $P G$. Breast cancer risk in premenopausal women is inversely associated with consumption of broccoli a source of isothiocyanates, but is not modified by GST genotype. J Nutr 2004; 134: 1134-8

51 Zhang Y, Talalay P, Cho CG, Posner GH. A major inducer of anticarcinogenic protective enzymes from broccoli: isolation and elucidation of structure. Proc Natl Acad Sci USA 1992; 89: 2399 - 403 
52 Zhang Y, Kensler TW, Choi CG, Posner GH, Talalay P. Anticarcinogenic activities of sulforaphane and structurally related synthetic norbornyl isothiocyanates. Proc Natl Acad Sci USA 1994; 91: 3147-50

53 Chung FL, Conaway CC, Rao CV, Reddy BS. Chemoprevention of colonic aberrant crypt foci in Fischer rats by sulforaphane and phenethyl isothiocyanate. Carcinogenesis 2000; 21: 2287-91

54 Fahey JW, Haristoy X, Dolan PM, Kensler TW, Scholtus I, Stephenson KK et al. Sulforaphane inhibits extracellular, intracellular, and antibioticresistant strains of Helicobacter pylori and prevents benzo[a]pyreneinduced stomach tumors. Proc Natl Acad Sci USA 2002; 99: 7610 - 5

55 Gills JJ, Jeffery EH, Matusheski NV, Moon RC, Lantvit DD, Pezzuto JM. Sulforaphane prevents mouse skin tumorigenesis during the stage of promotion. Cancer Lett 2006; 236: 72 -9

56 Thejass P, Kuttan G. Antimetastatic activity of sulforaphane. Life Sci 2006; 78: 3043 - 50

57 Barcelo S, Gardiner JM, Gescher A, Chipman JK. CYP2E1-mediated mechanism of anti-genotoxicity of the broccoli constituent sulforaphane. Carcinogenesis 1996; 17: 277-82

58 Brooks JD, Paton VG, Vidanes G. Potent induction of phase 2 enzymes in human prostate cells by sulforaphane. Cancer Epidemiol Biomarkers Prev 2001; 10: 949-54

59 Wattenberg $L W$. Inhibition of carcinogenic effects of polycyclic hydrocarbons by benzyl isothiocyanate and related compounds. J Natl Cancer Inst 1977; 58: $395-8$

60 Wattenberg $L W$. Inhibitory effects of benzyl isothiocyanate administered shortly before diethylnitrosamine or benzo[a]pyrene on pulmonary and forestomach neoplasia in A/J mice. Carcinogenesis 1987; 8: $1971-3$

61 Hirose M, Yamaguchi T, Kimoto N, Ogawa K, Futakuchi M, Sano M et al. Strong promoting activity of phenethyl isothiocyanate and benzyl isothiocyanate on urinary bladder carcinogenesis in F344 male rats. Int J Cancer 1998; 77: 773-7

62 Singh AV, Xiao D, Lew KL, Dhir R, Singh SV. Sulforaphane induces caspase-mediated apoptosis in cultured PC-3 human prostate cancer cells and retards growth of PC-3 xenografts in vivo. Carcinogenesis 2004; $25: 83-90$

63 Myzak MC, Tong P, Dashwood WM, Dashwood RH, Ho E. Sulforaphane retards the growth of human PC-3 xenografts and inhibits HDAC activity in human subjects. Exp Biol Med 2007; 232: 227-34

64 Xiao D, Zeng Y, Choi S, Lew KL, Nelson JB, Singh SV. Caspase dependent apoptosis induction by phenethyl isothiocyanate, a cruciferous vegetable derived cancer chemopreventive agent, is mediated by Bak and Bax. Clin Cancer Res 2005; 11: 2670-9

65 Xiao D, Lew KL, Zeng Y, Xiao H, Marynowski SW, Dhir R et al. Phenethyl isothiocyanate-induced apoptosis in PC-3 human prostate cancer cells is mediated by reactive oxygen species-dependent disruption of the mitochondrial membrane potential. Carcinogenesis 2006; 27: $2223-34$

66 Srivastava SK, Xiao D, Lew KL, Hershberger P, Kokkinakis DM, Johnson CS et al. Allyl isothiocyanate, a constituent of cruciferous vegetables, inhibits growth of PC-3 human prostate cancer xenografts in vivo. Carcinogenesis 2003; $24: 1665-70$

67 Fahey JW, Talalay P. Antioxidant functions of sulforaphane: a potent inducer of Phase II detoxication enzymes. Food Chem Toxicol 1999; 37: $973-9$

68 Keum YS, Yu S, Chang PPJ, Yuan X, Kim JH, Xu C et al. Mechanism of action of sulforaphane: inhibition of p38 mitogen-activated protein kinase isoforms contributing to the induction of antioxidant response element-mediated heme oxygenase-1 in human hepatoma HepG2 cells. Cancer Res 2006; 66: 8804-13

69 Gao X, Dinkova-Kostova AT, Talalay P. Powerful and prolonged protection of human retinal pigment epithelial cells, keratinocytes, and mouse leukemia cells against oxidative damage: the indirect antioxidant effects of sulforaphane. Proc Natl Acad Sci USA 2001; 98: 15221-6

70 Wang W, Wang S, Howie AF, Beckett GJ, Mithen R, Bao Y. Sulforaphane, erucin, and iberin up-regulate thioredoxin reductase 1 expression in human MCF-7 cells. J Agric Food Chem 2005; 53: 1417-21

71 Bacon JR, Plumb GW, Howie AF, Beckett GJ, Wang W, Bao Y. Dual action of sulforaphane in the regulation of thioredoxin reductase and thioredoxin in human HepG2 and Caco-2 cells. J Agric Food Chem 2007; 55 : $1170-6$

72 Miyoshi N, Takabayashi S, Osawa T, Nakamura Y. Benzyl isothiocyanate inhibits excessive superoxide generation in inflammatory leukocytes: implication for prevention against inflammation-related carcinogenesis. Carcinogenesis 2004; 25: 567-75
73 Nakamura Y, Ohigashi H, Masuda S, Murakami A, Morimitsu Y, Kawamoto $Y$ et al. Redox regulation of glutathione S-transferase induction by benzyl isothiocyanate: correlation of enzyme induction with the formation of reactive oxygen intermediates. Cancer Res 2000; 60: 219-25

74 Nakamura Y, Kawakami M, Yoshihiro A, Miyoshi N, Ohigashi H, Kawai K et al. Involvement of the mitochondrial death pathway in chemopreventive benzyl isothiocyanate-induced apoptosis. J Biol Chem 2002; 277: $8492-9$

75 Payen L, Courtois A, Loewert M, Guillouzo A, Fardel O. Reactive oxygen species-related induction of multidrug resistance-associated protein 2 expression in primary hepatocytes exposed to sulforaphane. Biochem Biophys Res Commun 2001; 282: 257-63

76 Singh SV, Srivastava SK, Choi S, Lew KL, Antosiewicz J, Xiao D et al. Sulforaphane-induced cell death in human prostate cancer cells is initiated by reactive oxygen species. J Biol Chem 2005; 280: 19911 - 24

77 Pham NA, Jacobberger JW, Schimmer AD, Cao P, Gronda M, Hedley DW. The dietary isothiocyanate sulforaphane targets pathways of apoptosis, cell cycle arrest, and oxidative stress in human pancreatic cancer cells and inhibits tumor growth in severe combined immunodeficient mice. Mol Cancer Ther 2004; 3: 1239-48

78 Yeh CT, Yen GC. Effect of sulforaphane on metallothionein expression and induction of apoptosis in human hepatoma HepG2 cells. Carcinogenesis 2005; 26: $2138-48$

79 Kim H, Kim EH, Eom YW, Kim WH, Kwon TK, Lee SJ et al. Sulforaphane sensitizes tumor necrosis factor-related apoptosis-inducing ligand (TRAIL)-resistant hepatoma cells to TRAIL-induced apoptosis through reactive oxygen species-mediated up-regulation of DR5. Cancer Res 2006; 66: $1740-50$

80 Cho SD, Li G, Hu H, Jiang C, Kang KS, Lee YS et al. Involvement of c-Jun $\mathrm{N}$-terminal kinase in G2/M arrest and caspase-mediated apoptosis induced by sulforaphane in DU145 prostate cancer cells. Nutr Cancer 2005: 52: $213-24$

81 Xiao D, Vogel V, Singh SV. Benzyl isothiocyanate-induced apoptosis in human breast cancer cells is initiated by reactive oxygen species and regulated by Bax and Bak. Mol Cancer Ther 2006; 5: 2931-45

82 Trachootham D, Zhou Y, Zhang H, Demizu Y, Chen Z, Pelicano H et al. Selective killing of oncogenically transformed cells through a ROSmediated mechanism by beta-phenylethyl isothiocyanate. Cancer Cell 2006; 10: $241-52$

83 Chang WH, Liu JJ, Chen CH, Huang TS, Lu FJ. Growth inhibition and induction of apoptosis in MCF-7 breast cancer cells by fermented soy milk. Nutr Cancer 2002; 43: 214-26

84 Salvi M, Brunati AM, Clari G, Toninello A. Interaction of genistein with the mitochondrial electron transport chain results in opening of the membrane transition pore. Biochim Biophys Acta 2002; 1556: 187 96

85 Macho A, Blazquez MV, Navas P, Munoz E. Induction of apoptosis by vanilloid compounds does not require de novo gene transcription and activator protein 1 activity. Cell Growth Differ 1998; 9: 277-86

$86 \mathrm{Kim} \mathrm{S}$, Moon A. Capsaicin-induced apoptosis of H-ras-transformed human breast epithelial cells is Rac-dependent via ROS generation. Arch Pharm Res 2004; 27: 845-9

87 Hail Jr. N, Lotan R. Examining the role of mitochondrial respiration in vanilloid-induced apoptosis. J Natl Cancer Inst 2002; 94: 1281 -92

88 Fujisawa S, Atsumi T, Ishihara M, Kadoma Y. Cytotoxicity, ROS-generation activity and radical-scavenging activity of curcumin and related compounds. Anticancer Res 2004; 24: 563-9

89 Shishodia S, Chaturvedi MM, Aggarwal BB. Role of curcumin in cancer therapy. Curr Probl Cancer 2007; 31: 243-305

90 Ahsan H, Parveen N, Khan NU, Hadi SM. Pro-oxidant, anti-oxidant and cleavage activities on DNA of curcumin and its derivatives demethoxycurcumin and bisdemethoxycurcumin. Chem Biol Interact 1999; 121: $161-75$

91 Bhaumik S, Anjum R, Rangaraj N, Pardhasaradhi BVV, Khar A. Curcumin mediated apoptosis in AK-5 tumor cells involves the production of reactive oxygen intermediates. FEBS Lett 1999; 456: 311 - 4

92 Atsumi T, Fujisawa S, Tonosaki K. Relationship between intracellular ROS production and membrane mobility in curcumin- and tetrahydrocurcumin-treated human gingival fibroblasts and human submandibular gland carcinoma cells. Oral Dis 2005; 11: 236-42

93 Atsumi T, Tonosaki K, Fujisawa S. Comparative cytotoxicity and ROS generation by curcumin and tetrahydrocurcumin following visiblelight irradiation or treatment with horseradish peroxidase. Anticancer Res 2007; 27: $363-71$ 
94 Chen J, Wanming D, Zhang D, Liu Q Kang J. Water-soluble antioxidants improve the antioxidant and anticancer activity of low concentrations of curcumin in human leukemia cells. Pharmazie 2005; 60: 57-61

95 Elchuri S, Oberley TD, Qi W, Eisenstein RS, Roberts LJ, Van Remmen H et al. CuZnSOD deficiency leads to persistent and widespread oxidative damage and hepatocarcinogenesis later in life. Oncogene 2005; 24: 367-80

96 Van Remmen H, Ikeno $Y$, Hamilton M, Pahlavani M, Wolf $N$, Thorpe SR et al. Life-long reduction in MnSOD activity results in increased DNA damage and higher incidence of cancer but does not accelerate aging. Physiol Genomics 2003; 16: 29- 37

97 Ishii $K$, Zhen LX, Wang DH, Funamori Y, Ogawa K, Taketa K. Prevention of mammary tumorigenesis in acatalasemic mice by vitamin $\mathrm{E}$ supplementation. Jpn J Cancer Res 1996; 87: 680-4

98 Egler RA, Fernandes E, Rothermund K, Sereika S, de Souza-Pinto $N$ Jaruga $P$ et al. Regulation of reactive oxygen species, DNA damage, and c-myc function by peroxiredoxin 1 . Oncogene 2005; 24: 8038 - 50

99 Ough M, Lewis A, Zhang Y, Hinkhouse MM, Ritchie JM, Oberley LW et al. Inhibition of cell growth by overexpression of manganese superoxide dismutase (MnSOD) in human pancreatic carcinoma. Free Radic Res 2004; 38: 1223 - 33

100 Venkataraman S, Jiang X, Weydert C, Zhang Y, Zhang HJ, Goswami PC et al. Manganese superoxide dismutase overexpression inhibits the growth of androgen-independent prostate cancer cells. Oncogene 2005; $24: 77-89$
101 Cooke MS, Evans MD, Dizdaroglu M, Lunec J. Oxidative DNA damage: mechanisms, mutation, and disease. FASEB J 2003; 17: 1195 - 214

102 Evans MD, Dizdaroglu M, Cooke MS. Oxidative DNA damage and disease: induction, repair and significance. Mutat Res 2004; 567: 1 - 61

103 Dizdaroglu M, Jaruga P, Birincioglu M, Rodriguez H. Free radical-induced damage to DNA: mechanisms and measurement. Free Radic Biol Med 2002; 32: 1102 - 15

104 Hawkins CL, Davies MJ. Hypochlorite-induced damage to DNA, RNA, and polynucleotides: formation of chloramines and nitrogen-centered radicals. Chem Res Toxicol 2002; 15: 83-92

105 Kawai Y, Morinaga H, Kondo H, Miyoshi N, Nakamura Y, Uchida Ket al. Endogenous formation of novel halogenated 2'-deoxycytidine. Hypohalous acid-mediated DNA modification at the site of inflammation. J Biol Chem 2004; 279: 51241 - 9

106 Doulias PT, Barbouti A, Galaris D, Ischiropoulos H. SIN-1-induced DNA damage in isolated human peripheral blood lymphocytes as assessed by single cell gel electrophoresis (comet assay). Free Radic Biol Med 2001; 30: 679-85

107 Xiao D, Lew KL, Kim YA, Zeng Y, Hahm ER, Dhir R et al. Diallyl trisulfide suppresses growth of PC-3 human prostate cancer xenograft in vivo in association with Bax and Bak induction. Clin Cancer Res 2006; 15: $6836-43$

108 Choi S, Singh SV. Bax and Bak are required for apoptosis induction by sulforaphane, a cruciferous vegetable derived cancer chemopreventive agent. Cancer Res 2005; 65: 2035 - 43 